Journal of International Medical Research \& Health Sciences, 2021, 1(1): 1-6

Case Report

\title{
Ovarian necrosis of both ovaries with uterine ischemic changes following B-Lynch sutures: A rare complication and review of literature

\author{
Rajshree Dayanand Katke ${ }^{1 *}$
} \\ ${ }^{1}$ Department of Obstetrics and Gynaecology, Grant Govt Medical College and Sir JJ Group of hospitals, Mumbai, Maharashtra, India, 400008 \\ *Corresponding E-mail: drrajshrikatke@gmail.com
}

\begin{abstract}
Pospartum haemorrhage has been the leading direct cause of maternal morbidity and mortality. In 1997, B-Lynch initiated the use of uterine compression sutures for postpartum hemorrhage. Uterine compression sutures have accomplished hemostasis while retaining fertility in many women and thus their efficacy and security have been timetested. Uterine compression sutures have helped to expressively reduce the number of obstetric hysterectomy. These uterine compression sutures can cause complication like hematometra, pyometra, Asherman's syndrome, uterine necrosis. Each suture has both advantages as well as disadvantages and hence obstetricians must be aware of the fundamental characteristics of various sutures. In this case report, we explain the importance of knowing the proper surgical technique and the essence of anatomy, in order to prevent complications.
\end{abstract}

Keywords: B Lynch, postpartum hemorrhage, cesarean, ovarian necrosis, complications

Received: 16 April, 2021

Accepted: 29 April, 2021

Published: 07 May, 2021

\section{Introduction}

Postpartum hemorrhage (PPH) is one of the foremost causes of maternal morbidity and mortality worldwide [1, 2]. The maiden treatments for PPH are to administer uterotonic agents, uterine fundal massage, or bi-manual uterine compression [1,2]. Intrauterine gauze tamponade or an intrauterine balloon catheter may be useful at times but not necessarily in every case $[1,2]$. When these relatively non-invasive treatments do not achieve hemostasis, the next step is the use of more invasive treatments requiring laparotomy, including devascularization, iliac artery ligation, or finally, hysterectomy [2]. Transarterial embolization has also become a decent choice [1, 2].

The B-Lynch uterine suture brace is a relatively new technique used for the treatment of postpartum haemorrhage before the advent of B-Lynch suture obstetric hysterectomy was done for atonic PPH. B-Lynch suture should be exasperated in cases of atonic PPH before proceeding to stepwise ligation of the uterine vasculature. The advantage of B-lynch suture is that it appears to be effective to control severe persistent PPH following the failure of vessel ligation before considering obstetric hysterectomy [3].

\section{Case History}

As per the history narrated by patient and relatives, 19 years female with caesarean done on 5 December 2018 at 03:00 PM in Civil Hospital Alibagh, with still born baby with referral letter mentioning "day 3 postnatal post caesarean with thrombocytopenia for further management with blood loss through drain".

Caesarean was done in view of postdatism with non-progress of labour, still birth at time of caesarean. Post caesarean 
patient had severe blood loss through drain in abdomen, so 3 pint whole blood, 4 pint packed cell volume, and 5 pint fresh frozen plasma was given.

Obstetric history- Patient was married since 1 year, primparous women

Details about antenatal registration and immunisation were unavailable.

On examination, she was pale, obese, tachycardia was present. Her blood pressure was 100/60 mm Hg.

On Systemic examination, cardiovascular examination, tachycardia was present, Hearts sounds were normal. On respiratory examination, air entry was bilaterally equal, chest was clear. On per abdomen examination, abdomen was distended, uterus size was 26 weeks gestational size, tenderness was present. Stitches of caesarean section were present. On per speculum examination, bleeding ++. On per vaginum examination, uterus size was 26-28 weeks size, tenderness was present and it was intermittently flabby.

Patient was shifted to operation theatre immediately for exploration as patient was getting hemodynamically unstable. Skin sutures were removed. Inverted T incision was necessitated because of over distended uterus which could not be exteriorised through the transverse incision. There was hematoma and collected blood in between the rectus muscle and rectus sheath. Then the peritoneum was opened. There was mild hemoperitoneum, the uterus was over distended, the B-Lynch stitches were present. Both the ovaries were congested and at the verge of becoming gangrenous. Both the fallopian tubes were congested and blackened. Hot mops were used, the uterus was becoming flabby, the suture line over the lower segment were removed as the blood was coming through the uterine cavity. Uterine sutures of lower segment incision were removed and there was blood and blood clots were present in the distended uterine cavity. The myometrial rugosity was lost and left side uterine wall was pale, congested, and very thinned out, as it seems to be getting ruptured. All the uterine cavity was evacuated. Uterine massage was given, methy-ergometrine and prostaglandin F2 alpha, both intra muscularly and intra myometrial. Injection Pitocin drip was started. Bilateral uterine arteries were ligated. Then the uterus started contracting and the bleeding stopped. The color of the ovaries improved after removal of stitch and maintaining of the circulation. Haemostasis was achieved and abdomen was closed after putting drain.

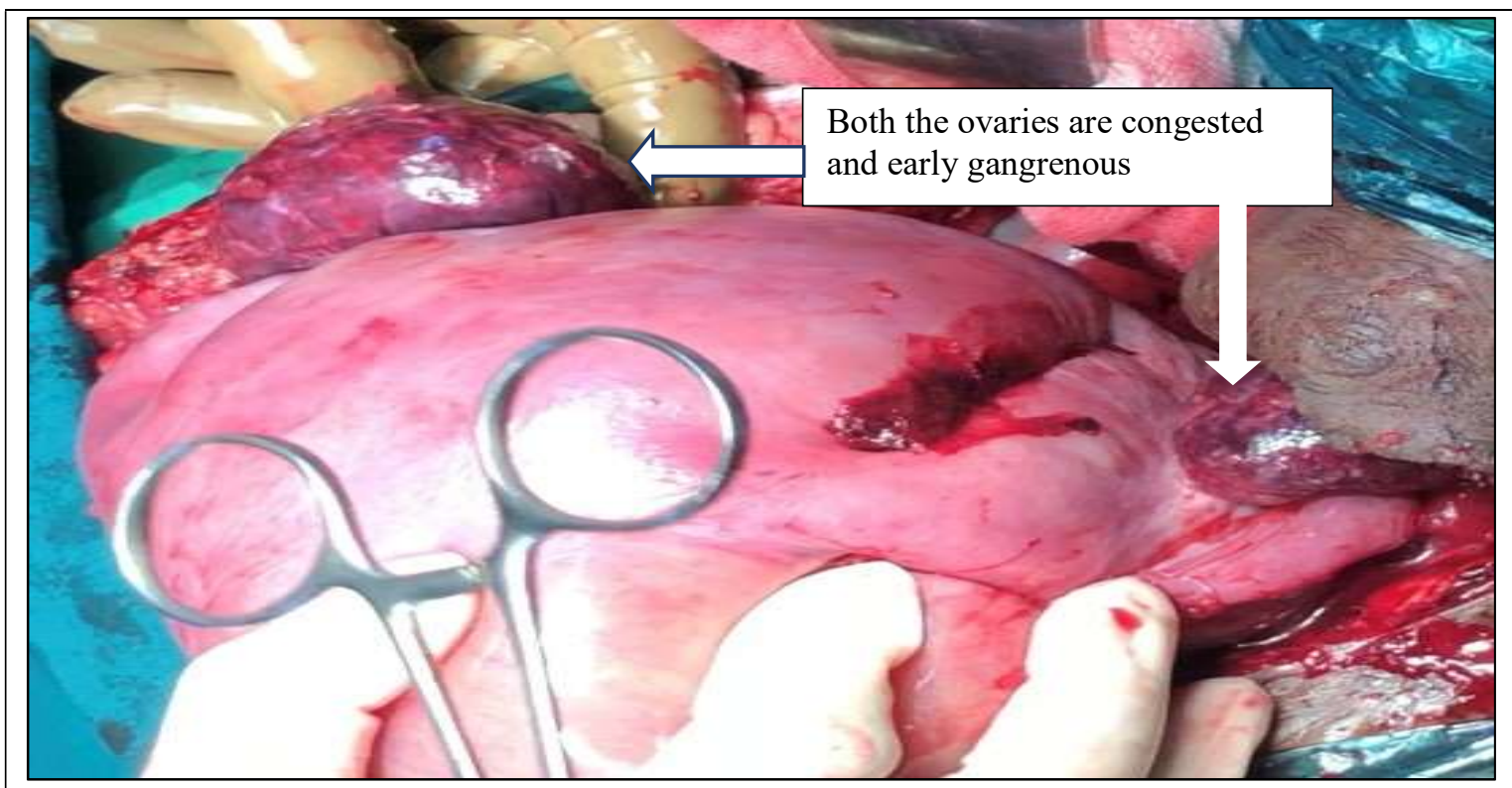

Figure 1: Intra operative picture showing congested and gangrenous ovaries. 


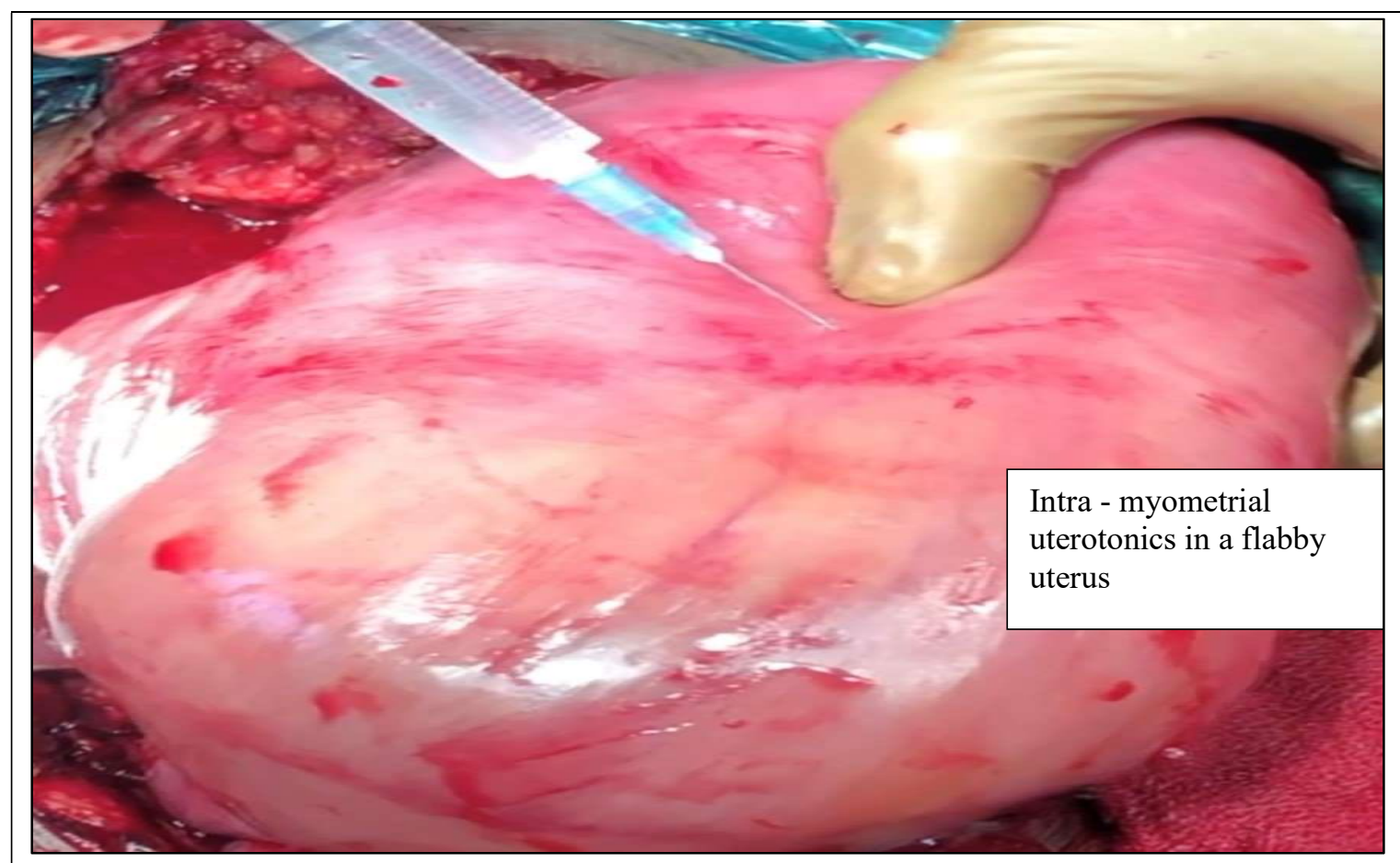

Figure 2: Intra operative picture of flabby uterus managed with uterotonics.

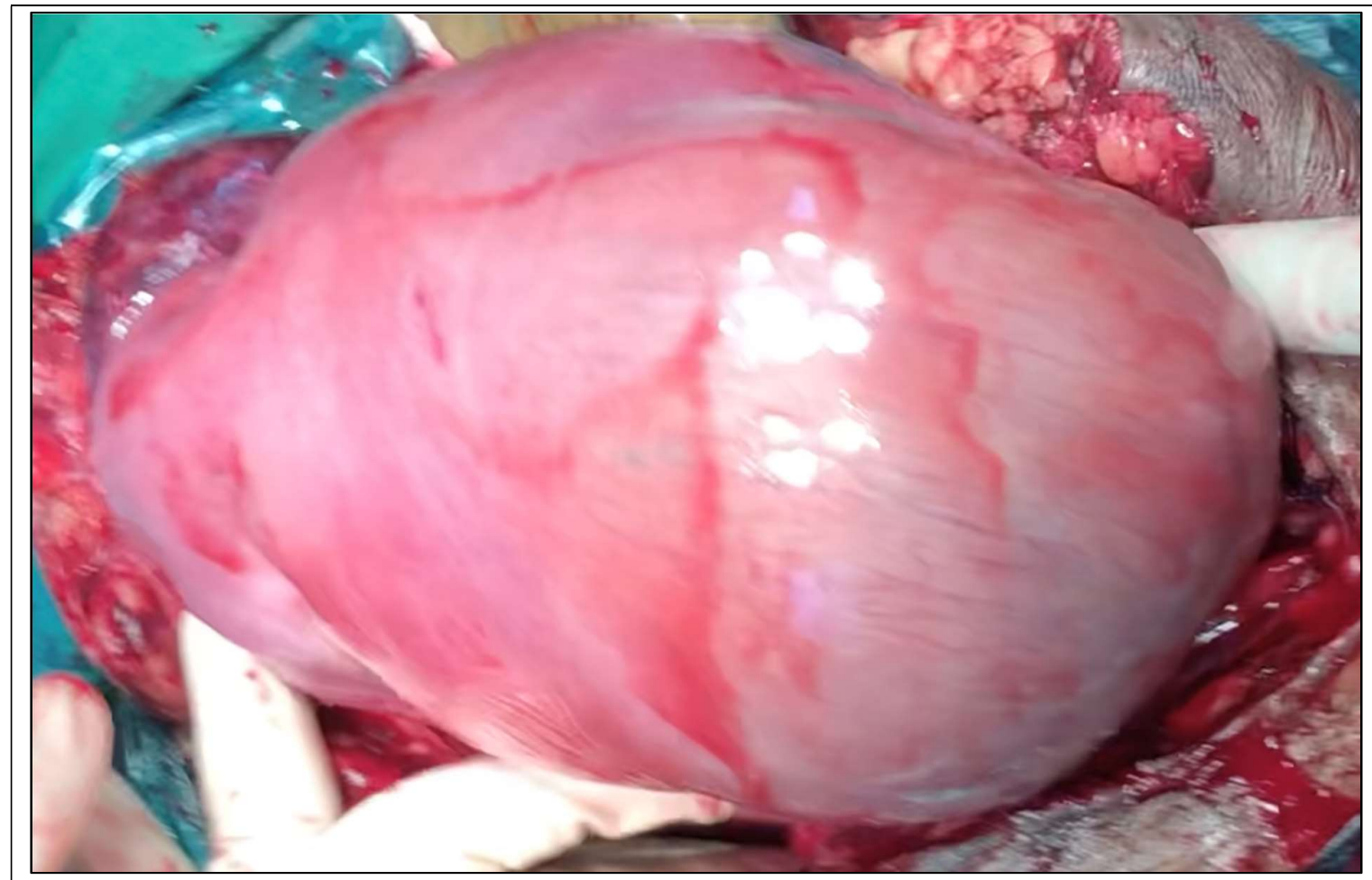

Figure 3: Intra operative picture depicting over distended uterus filled with blood clots requiring Inverted $T$ incision on skin 


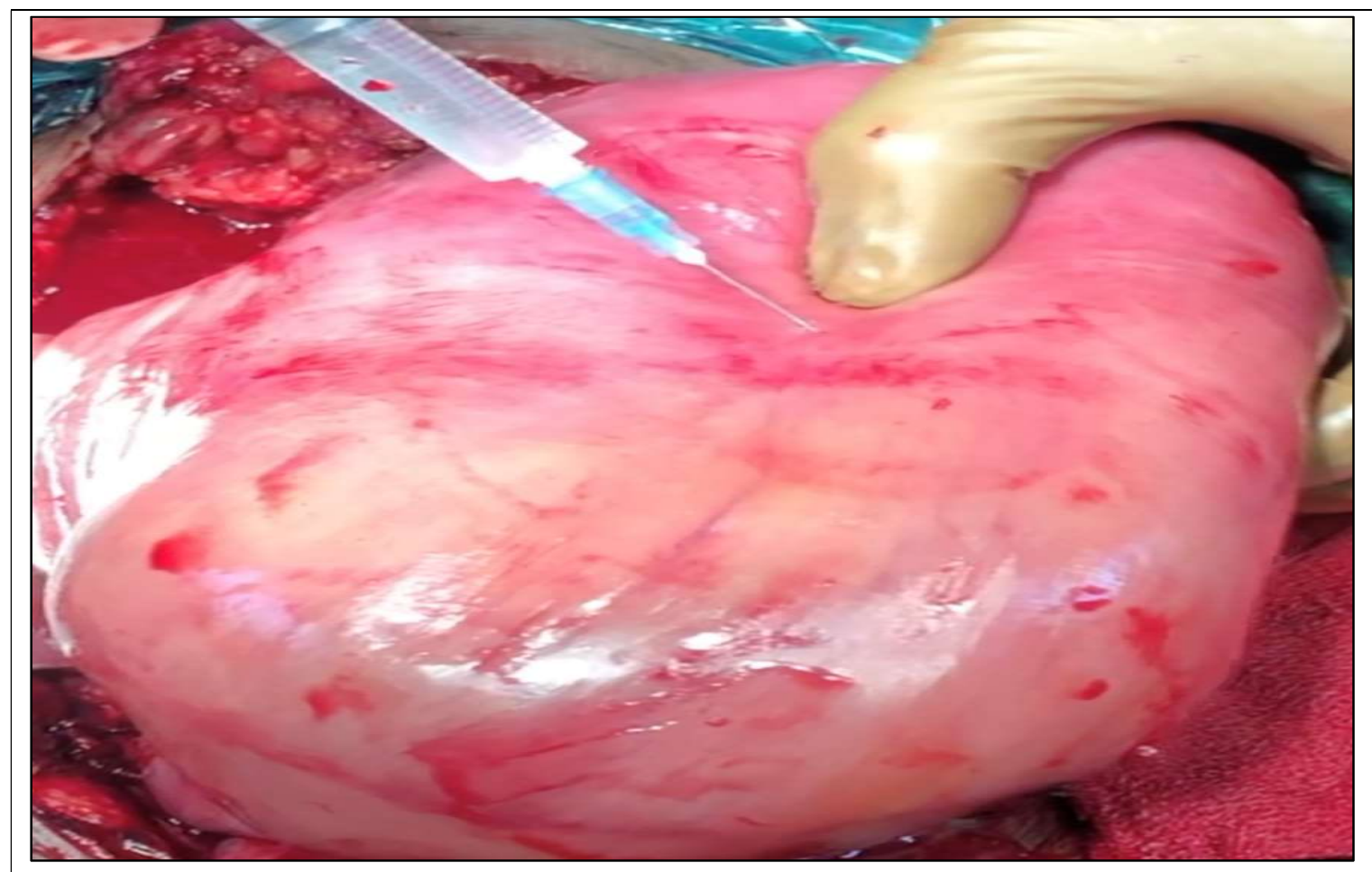

Figure 4: Flabby, pale, and thinned-out uterine segment.

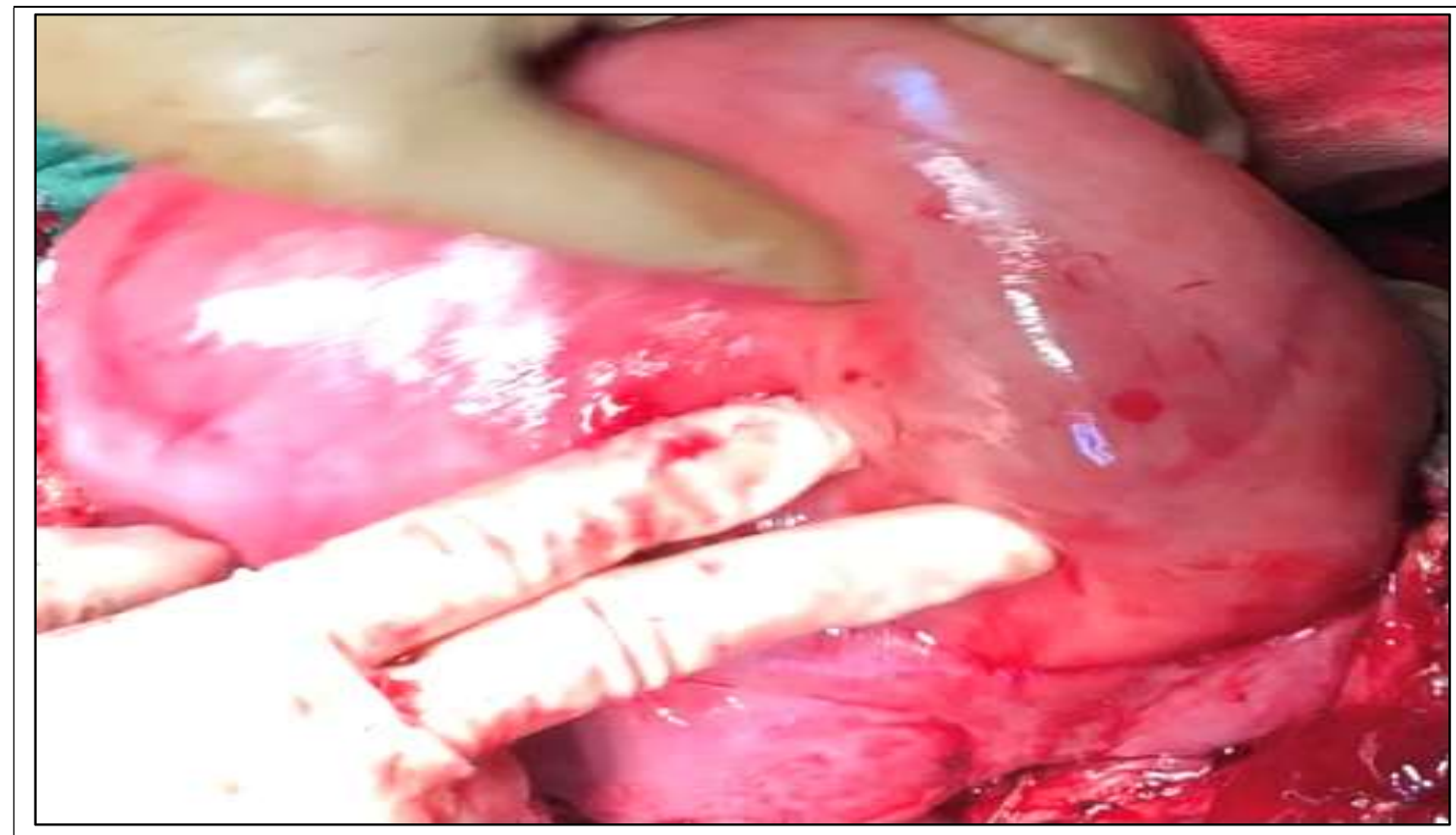

Figure 5: Intra-operative picture depicting extremely thinned walled uterus.

Post operatively, patient was monitored closely, blood was given

Patient was discharged eventually after suture removal. 


\section{Discussion:}

We report the rare status of a patient with history of atonic post - partum hemorrhage managed with a compressing uterine sutures which led to a rare complication of ovarian necrosis. However the timely re-exploration of the patient led to a timely management of the case and preserving the uterus as well as the ovary of the patient. A prior consent for publication of the case report was taken.

B-Lynch and colleagues in 1997, described this surgical technique for atonic uterus. In this, pair of vertical brace sutures is secured about the uterus with no 2 chromic catgut. This suture works by compressing the anterior and posterior wall placental bed thus reducing the uterine blood loss the objective of this surgical technique is to compress uterus without occluding uterine arteries. The success rate of this suture is $86.4 \%$ in avoiding obstetric hysterectomy and thus this suture are widely recommended for atonic PPH [4].

To define PPH blood loss should be of more than $500 \mathrm{ml}$ after normal delivery and more $1000 \mathrm{ml}$ during cesarean section and this ensues in around 5\% of all deliveries [5]. It is a theoretically dangerous obstetric complication and is related with risk of morbidity and mortality.

Atonic uterus is the most common and avoidable cause of postpartum hemorrhage constituting around $80 \%$ which usually responds to uterotonics drugs [6]. However few patients may need surgical intervention, second-line therapy comprises packing of the uterine cavity, selective ligation of the uterine vasculature or referral to interventional radiologist for embolization of the major blood vessels [7, 8]. B-Lynch sutures and its modifications are new surgical modality in patients with PPH.

B-Lynch suture requires skilled surgeon and un-sutured lower segment incision in comparison to its modification, which is time consuming and associated with increased blood loss. The combination of compression sutures and uterine artery ligation are more likely result into ischemia leading to necrosis and inflammation, but no mortality has been reported as of now in association with these compression sutures [9].

Although the incidence of higher order caesareans like previous 3 or 4 is low but is bound to increase owing to the injudicious use of caesarean sections. A study by Dr Katke et al showed a significant increase in maternal morbidity with an increasing number of caesarean sections [10].

The incidence of caesarean section is on a rising trend entitling women to be a case of "previous caesarean" and also eventually increasing the incidences of placenta previa and placenta accrete syndromes. As a result of this, the incidence of complications are also rising like the present case reported and also the incidence of placenta percreta [11].

\section{Conclusion:}

This is a rare case of complication arising from the B lynch sutures. Although the management of atonic postpartum haemorrhage is with uterotonics, timely decision and appropriate patient selection is of utmost importance while chosing the fertility sparing surgeries for the management of postpartum hemorrhage.

\section{DECLARATIONS}

Conflicts of Interest: The authors declared no potential conflicts of interest with respect to the research, authorship, and/or publication of this article.

Funding: None 


\section{REFERENCES}

[1] Mousa HA, Alfirevic Z. Treatment for primary postpartum haemorrhage. Cochrane Database Sys Rev. 2007; Issue 1: CD003249.

[2] Cunningham FG, Leveno KJ, Bloom SL, Hauth JC, Rouse DJ, Spong CY. Obstetric hemorrhage. In: Cunningham FG, Leveno KJ, Bloom SL, Hauth JC, Rouse DJ, Spong CY (eds). Williams obstetrics, 23rd edn. New York: McGraw Hill Medical, 2010. pp. 757-803.

[3] Sentilhes L, Gromez A, Razzouk K, Resch B, Verspyck E, Marpeau L. B-Lynch suture for massive persistent postpartum hemorrhage following stepwise uterine devascularization. Acta Obstet Gynec Scand. 2008; 87(10):1020-6.

[4] Sentilhes L, Gromez A, Razzouk K, Resch B, Verspyck E, Marpeau L. B-Lynch suture for massive persistent postpartum hemorrhage following stepwise uterine devascularization. Acta Obstet Gynec Scand. 2008; 87(10):1020-6.

[5] Arduini M, Epicoco G, Clerici G, Bottaccioli E, Arena S, Affronti G. B-Lynch suture, intrauterine balloon, and endouterine hemostatic suture for the management of postpartum hemorrhage due to placenta previaaccreta. Int $\mathrm{J}$ Gynaecol Obstet. 2010; 108:191-3.

[6] Obstetric haemorrhage Williams obstetrics 22nd edition, McGraw-Hill Medical Publication division; 2005:823-24.

[7] Condous GS, Arulkumaran S. Medical and conservative surgical management of postpartum hemorrhage. J Obstet Gynaecol Can. 2003; 25:931-6.

[8] B-Lynch C, Coker A, Lawal AH, Abu J, Cowen MJ. The B-Lynch surgical technique for the control of massive postpartum haemorrhage: an alternative to hysterectomy? Five cases reported. Br J Obstet Gynaecol. 1997; 104:372-5.

[9] Satia MN, Vibha S. Uterine necrosis in a case of B-Lynch brace suture. Int J Reprod Contracept Obstet Gynecol. 2016; 5(7):2466-69.

[10] Rajshree DK. A Study on the Fetomaternal Outcome in Cases of Previous Three Caesarean Section Mortality; 2:3.

[11] Katke R. Placenta Percreta And Its Successful Outcome: A Rare And Difficult Case Report And With Review Of Literature. Natl J Integr Res Med 2021; Vol.12(1): 91-94 